\title{
The Primacy of Institutional Explanation of Chinese Outward FDI: Is It Understated or Overstated?
}

\section{Lin Cui}

Australian National University, Australia

KEYWORDS China, foreign direct investment, institutional perspectives, quantitative analysis

\section{INTRODUGTION}

An institutional perspective has been increasingly adopted in recent studies to explain various aspects of internationalization activities of firms from emerging economies (Meyer \& Peng, 2016; Peng, Wang, \& Jiang, 2008), particularly China (Cui \& Jiang, 2012; Morck, Yeung, \& Zhao, 2008). Scholars often claim that the role of institutions in emerging economy firms' internationalization is understated, hence more research is needed. In this commentary, which reflects on the intended contributions and theoretical and empirical issues of Buckley, Yu, Liu, Munjal, and Tao (2016), I aim to extend a discussion on whether and when such institutional explanations can be overstated. I focus on three issues: (1) conceptualization of institutions, (2) theorizing institutional effects, and (3) testing institutional effects. On each of these issues, I start by providing an overview of some common challenges in the literature. I then focus specifically on the paper as an illustration of how some of these challenges may be manifested. This is then followed by some recommendations for future research. Overall, I argue that pitfalls related to the conceptualization, theorizing and testing of institutional effects can lead researchers to overstate the institutional effects on firm strategic behaviors. These pitfalls can be avoided if researchers clarify the theoretical boundary of the institutional argument they adopt, properly model the institutional effects while taking into consideration other theoretically relevant constructs and mechanisms, and employ empirical design to overcome measurement errors and selection biases when testing not only the statistical significance, but also substantive (economic) significance of institutional effects. 


\section{GONGEPTUALIZING INSTITUTIONS}

\section{Overview of the Issue}

The first step to establish an institutional explanation of firm strategic behaviors is to define what institutions are. Different institutional perspectives are frequently adopted by management scholars (Kostova \& Hult, 2016). These perspectives derive from various theoretical roots and differ with each other in their core assumptions, levels of analysis, theoretical mechanisms, and related strengths and limitations. The four most popular perspectives are (1) new institutional economics, which is based on North's (1990) conceptualization of institutions as formal and informal rules that shape the incentives driving human exchange, (2) sociological institutional theory that sees institutions as pressures for legitimacy on organizations and individuals (DiMaggio \& Powell, 1983; Meyer \& Rowan, 1977; Scott, 1995), (3) comparative institutionalism, which regards institutions as economic inputs rather than constraints and focuses on institutional difference in type rather than in degree (Hall \& Soskice, 2001; Jackson \& Deeg, 2008; Whitley, 1999), and (4) co-evolutionary perspective, which argues that institutions are not entirely exogenous of the organizations, but are avenues where the latter can extend their influence to shape the environment (Nelson \& Sampat, 2001). For a more detailed discussion and systematic comparison of these different conceptualizations of institutions, please refer to Hotho and Pedersen (2012), Kostova and Hult (2016), and Meyer and Peng (2016).

Given the existence of these different conceptualizations of institutions, there is a risk of overstating institutional effect when multiple conceptualizations are mixed in a single study. If researchers do not clarify the specific conceptualization they adopt, but allow for loose boundary between multiple conceptualizations, they are likely to incorporate variables that share the common label of 'institution' but differ theoretically on the assumptions and mechanisms underlying their effects on firm behaviors. As a result, such studies are likely to reach conclusions that overstate the institutional effects. For example, if researchers regard institutions as both economic incentives and legitimacy pressures, they can potentially label a wide range of environmental variables as institutional factors which can be internal or external to the firm, perceptual or objective in nature, and across different levels of analysis (country institutions vs. social/industrial fields). The pitfall of taking such an omnipresent view of institutions is that the researchers will have to make different behavioral assumptions of the firm (bounded rational actors maximizing economic gains vs. socially embedded actors seeking legitimacy for survival and resources) which are theoretically incompatible, potentially leading to logically inconsistent arguments that overstate institutional effects.

\section{Conceptualization Issue Illustrated in Buckley et al. (2016)}

The first intended contribution of Buckley et al. (2016) is to examine the effect of macro-level (i.e., country-level) institutions on Chinese outward FDI location 
and volume, by modeling institutional factors at both home and host countries. However, when identifying the home and host institutional factors, the authors use different conceptualizations of institutions.

The host institutional factor is the macro-level political risk, which is conceptualized as a lack of constraints on opportunistic and discriminating behaviors of host country government that subsequently increases transaction costs and liabilities of foreignness of Chinese investors. This conceptualization is in line with the new institutional economics perspective, with the assumption that firms are incentivized by the host institutional condition to make their location and volume decisions that maximize economic returns. In contrast, the home institutional factor captured in this study is the home country 'go global' policy, which is conceptualized as a pushing factor. This is in line with the sociological institutional theory that sees institutions as pressures, with the assumption that firms seek legitimacy with the institution to maintain survival and secure resources (e.g., government support).

By adopting a mixture of two different conceptualizations of institutions, this paper makes very different behavioral assumptions of the firm, which may lead to very different conclusions. For example, if we follow the sociological institutional theory and see Chinese outward FDI mainly as firms' homegovernment-oriented legitimizing effort or a herding behavior (i.e., responding to isomorphic pressure), with no or little consideration of long-term economic gains, then it appears that the Chinese firms are economically irrational and excessive risk-takers. However, if we follow the new institutional economics perspective and theorize that firms are incentivized by institutional conditions to maximize profit, then entering politically risky host countries is not, as the authors claim, shortsighted and perverse behavior, because, as the authors also acknowledge, that [some] Chinese firms have sufficient financial buffer to appropriate economic rent in risky host countries while alternative institutions (i.e., bilateral political relations between China and the focal host country) are in place to reduce the potential risk. In fact, such behaviors of Chinese firms are highly rational as they are incentivized by the risky host institutional environment to exploit their ability of appropriating economic rents in such an environment, which is a competitive advantage against other foreign investors or even local firms. Concluding that institutional influence causes irrational firm behaviors is therefore incorrect, or at best an overstatement of the true institutional effect.

\section{Recommendations for Future Research on Conceptualizing Institutions}

Three recommendations are proposed for future research. First and most obviously, future studies should always clarify which conceptualization of institutions is taken as the theoretical basis for the study. Without a clear and consistent conceptualization, 
researchers run the risk of using 'institution' as a common label and overstate the institutional effects. Second, researchers should justify their choice when conceptualizing institutions. Different conceptualizations suit different levels of analysis and can have different explanatory power for answering the research questions at hand. Third, researchers should take more explicit and formal approaches when integrating different institutional perspectives. Maintaining clarity and consistency when conceptualizing institutions does not mean studies should always adopt only one institutional perspective. Integrating multiple perspectives is not only possible but even desirable for theoretical advancement. For example, Ahmadjian (2016) integrates comparative institutionalism with sociological institutional theory to theorize multinational firms' responses to institutional complexity. However, when integrating institutional perspectives, instead of simply combining variables from different institutional perspectives, researchers should explain why these perspectives should be integrated and be explicit about implications for the underlying assumptions. For example, as new institutional economics and comparative institutionalism both focus on formal country-level institutions, they can be potentially integrated to capture the dual roles of formal institutions in regulating economic exchanges and providing economic inputs (Jackson \& Deeg, 2008).

\section{THEORIZING INSTITUTIONAL EFFEGTS}

\section{Overview of the Issue}

After clarifying what institutions are, their effects on firm behaviors can be theorized to form research hypotheses. Different types of institutional effects can be theorized. First, institutions can be theorized to have a universal direct effect on firm behaviors. The typical hypothesis is that as institutions change in one direction, firms on average will respond in a universal way. For example, Meyer et al. (2009) theorize that as market-supporting institutions in the host country strengthens, foreign entrants will become less likely to choose joint venture as an entry mode. Second, institutions can affect firms differently given heterogeneous strategic orientation and resource-dependency of firms on institutions, and as such, institutional effects can be theorized as contingent effects. The derived hypotheses recognize firm agency in forming heterogeneous responses to external intuitional influences (Cui \& Jiang, 2012; Oliver, 1991). Depending on which institutional perspective is adopted in the study, corresponding firm-level variables are identified to moderate the effects of institutions on firm behaviors. Third, institutions can be theorized as contextual variables that moderate the effects of other causal relationships informed by management theories. For example, Lin, Peng, Yang, and Sun (2009) theorize that the level of institutional development moderates the effects of network and learning on firms' merger and acquisition activities. Fourth, interaction of multiple dimensions or facets of institutions can affect firm behaviors. 
Theorizing interaction effects of institutions is based on the notion that institutions do not operate in isolation, but are often dependent on (or reinforced by) each other when influencing firm behaviors (Ang, Benischke, \& Doh, 2015; Hall \& Soskice, 2001; Spencer \& Murtha, 2005). The fifth possibility is to theorize institutional effects as mediated indirect effects. The logic follows that institutional environment promotes the development of context-specific firm resources and capabilities, which in turn leads to certain firm behaviors and/or performance outcomes. All five types of theorization of institutional effects can potentially receive empirical support and contribute to knowledge, depending on the specific research questions asked and the research context. However, when all other things are equal, I argue that the first type of theorization, namely a universal direct effect, runs the highest risk of over-generalization and consequently overstating the institutional effect.

\section{Theorization Issue Illustrated in Buckley et al. (2016)}

Buckley et al. (2016) hypothesizes home and host institutional effects on Chinese outward FDI location and volume as universal direct effects. The hypotheses concern the aggregated or average responses of Chinese firms to home country policy change, and to host country political risk. However, prior studies suggest that firms may respond to home and host institutional influences differently, which call for a contingency approach to theorizing the institutional effects. By focusing solely on the universal direct institutional effects, the authors miss out on the opportunity to investigate firm heterogeneity in responding to institutions, which lead to overstatement of institutional effects that may or may not apply to a variety of Chinese outward-investing firms.

Chinese firms do not necessarily respond to home policy in the same way. There are considerable differences between Chinese state-owned enterprises (SOEs) and private Chinese firms in terms of their capabilities and resource-dependency on the government. Logically, they would perceive different levels of pressure (pushing effect) from the 'go global' policy. Even among SOEs, research on variety of state capitalism (Li, Cui, \& Lu, 2014; Musacchio, Lazzarini, \& Aguilera, 2015) demonstrates how the evolving relationships between SOEs and home-country government vary across types of SOEs and over time. Removing firm-level heterogeneous response to home institutions from theorizing the home institutional effect is not an advancement of theory but a move backwards. Moreover, assuming received empirical support, this kind of hypothesis only reflects the host-country level aggregated effect of 'go global' policy on Chinese outward FDI (dependent variable measured at host country-year level), but carries no evidence to substantiate the universal claim that 'Chinese MNEs are shortsighted and show perverse behavior ... which may damage their long term profitability' (Buckley et al., 2016: Abstract).

Similarly, research has also shown that Chinese firms respond to host country institutional influence in a non-unified manner (Cui \& Jiang, 2012). Resource, 
experience, and strategic objective can alter a firm's risk tolerance level towards host country institutional environment. Non-significant result on the host institutional effect on FDI location choice could contain valuable information - it could be the case that the effect of host institution is non-monotonic, in the sense that Chinese SOEs, given their financial buffer and political assets, may be more risk tolerant and be attracted towards risk-associated benefits, while private Chinese firms may be more risk averse and will avoid investing in politically unstable host countries. Therefore, the resultant non-effect is not due to Chinese firms generally lacking risk sensitivity and economic rationality, but quite opposite, it is a result of different risk approaches of different kind of firms specifically implemented based on their diverging conditions. To me, this alternative explanation is more plausible than the universal claim by the authors. Overall, by theorizing only the universal direct institutional effects, the paper invites criticisms regarding over-simplification and has high risk of misinterpreting the results and overstating the findings.

\section{Recommendations for Future Research on Theorizing Institutional Effects}

Given that the relationship between institutions and firm behaviors is by nature a cross-level relationship, theorizing this relationship requires convincing arguments on a potentially long chain of logics. Accordingly, my first recommendation for future research in this regard is to avoid hypothesizing only the universal direct effect of institutions on firm behaviors. This type of hypothesis does not allow researchers to unpack the chain of logics and therefore, renders the theory development vulnerable to alternative explanations that may arise in every stage of the logic chain. My second recommendation is for researchers to keep investigating the contingent, contextual, and interaction effects of institutions, which I think is a healthy trend in the recent literature. Last but not least, I propose that the field can benefit from more studies that theorize the mediated causal pathway between institutions and firm behaviors. This type of study will help researchers dissect the logic chain of the cross-level relationship between institutions and firms, and identify contingencies that operate at different stages of the causal pathway, which can potentially lead to novel theoretical insights and more practically relevant managerial and policy implications. Overall, I believe it is more fruitful to theorize institutional effects in the nexus of theoretically relevant firm-level and institutional-level constructs, rather than to attempt to isolate a universal direct institutional effect.

\section{TESTING INSTITUTIONAL EFFEGTS}

\section{Overview of the Issue}

Researchers may be overstating the institutional effects if their empirical tests suffer from type I error. I identify four major sources of type I error that studies 
of institutional effects are particularly vulnerable to (although not exclusive to these studies). The first source is measurement error. Formal institutions are often measured by composite indices. Highly aggregated indices may measure a broader spectrum of institutional dimensions and environmental factors than the theoretical construct of interest. A statistically significant effect of the aggregated measure does not necessarily indicate an effect of the hypothesized institutional variable. The second source is lack of control, which may lead to violation of the conditional-independence $(\mathrm{CI})$ assumption when testing causal relationships. Specifically, firm strategic behavior is influenced by a multitude of not only institutional, but also firm resource and industrial factors (Peng, Sun, Pinkham, \& Chen, 2009). Type I error will emerge when important controls are missing from the empirical model. The third source is endogeneity. Not all institutional factors and policy changes are exogenous to the firm (see the co-evolutionary perspective of institutions), therefore, endogeneity issue may emerge from self-selection. Sample selection may also pose concerns when studies fail to capture observations from the untreated control group. The last source, which is not strictly a type I error issue, concerns the practice that researchers focus solely on statistical significance but do not assess and report substantive significance of causal effects (Bettis, Ethiraj, Gambardella, Helfat, \& Mitchell, 2015; Schwab, Abrahamson, Starbuck, \& Fidler, 2011). An institutional effect significantly different from zero may not be practically meaningful if the effect size is too small to make a noticeable impact on firm behaviors.

\section{Testing Issue Illustrated in Buckley et al. (2016)}

The empirical analysis of Buckley et al. (2016) suffers from some of the methodological pitfalls identified above. First, the empirical models are undercontrolled. For example, ore and fuel are not the only resource endowment factors that may attract Chinese outward FDI. Depending on the industry, agricultural resources and uncodified intangible assets are also necessary controls. Regional and global macroeconomic conditions, such as exchange rate fluctuation, regional and global financial crisis (both the Asian financial crisis and the GFC are captured in the observation time window of this study) may significantly affect FDI outflow from China into specific foreign locations.

Second, the statistical significance and substantive significance of the tested effects are not correctly assessed. Hla concerns the effect of home policy change, i.e., the 'go global' policy. Only showing that patents positively influence FDI location in the post-policy period does not indicate that firms' FDI location preferences have changed due to that policy. A proper test of this hypothesis requires a differencein-difference approach and the assessment of the statistical significance of a policypatents interaction term. H1b is unsupported. $\mathrm{H} 2 \mathrm{a}$ is not testable - it states that Chinese FDI location choice is not negatively affected by host political risk, which 
means that it is either (1) positively affected by host political risk, or (2) is unaffected by host political risk. Scenario (2) is not testable as null hypothesis significance test cannot produce support for a non-effect. Hence, among the four hypotheses tested in the paper, only $\mathrm{H} 2 \mathrm{~b}$ received partial support (from model 2 but not model 1) of its statistical significance. Regarding the reporting of statistical significance, it is also worth noting that management scholars and leading journals call for more transparency (see Bettis et al., 2016; Lewin, 2016), requiring researchers to report the actual p-values (i.e., the margin of type I error) and/or interpret the confidence intervals, as oppose to simply stating the p-value cutoff levels. This practice is not followed by the authors.

Third, the substantive significance of the statistically significant effect (i.e., H2b) is questionable. There is no assessment of the effect size, for the whole model or the individual variables of interest. We do not know how much variance is explained by the model and how much of this is contributed by the host political risk. This is again deviating from the recommended practice for management research (see Bettis et al., 2016; Lewin, 2016). Moreover, the negative coefficient of host country legal and social order (model 2 of table 3 ) only means that the overall Chinese FDI inflow volume increases as the host country political risk increases, but has no indication of the size of individual M\&A deals. It could be the case that the increase in overall volume was caused by increase in number of M\&As but not the (average) size of M\&As. Hence the results render no substantive support to H2b. In sum, none of the hypotheses is convincingly supported, which suggests that the interpretations of the study findings are false and its claim of the institutional effects is overstated.

Third, endogeneity issue is recognized but poorly handled in the study. The authors correctly identified the potential sample selection problem and try to use the Heckman procedure to overcome it. However, the Heckman procedure is incorrectly implemented in both stages. In the first stage, at least one exogenous selection variable should be included, which should be related to stage 1 selection but not to stage 2 outcome. The entry cost variable is presumably correlated with the stage 2 outcome, namely investment volume. Intuitively, high entry costs will negatively influence investment size. Moreover, the entry cost variable has conceptual overlap with the main explanatory variable (i.e., host political risk). Some sub-dimensions of the entry cost index concerns strength of legal rights and investor protection (see World Bank's Doing Business report). The two variables may be correlated, leading to multicollinearity problem in stage 1 model. Furthermore, the matching process in stage 1 is vague and unnecessary. The point of conducting the Heckman procedure is to include all missing observations in stage 1, but not selected missing observations. Following on the stage 1 , stage 2 estimation should be based on the selected sample, but not the full sample. An example of implementing Heckman procedure for sample selection correction is provided in Yang, Lin, and Lin (2010). 


\section{Recommendations for Future Research on Testing Institutional Effects}

For researchers to produce reliable findings with regard to institutional effects in future studies, I recommend four practices. The first is to use correct measures that match the conceptualization of the institutional variables being studied. Cautious should be exercised when using highly aggregated institutional indices, despite the fact that their sub-dimensions may be correlated. Using refined proxies or selected sub-dimension indices may help researchers improve the measurement precision in their studies. Second, researchers should identify and include necessary controls in their empirical model. Of course, it is not possible to include all potential control variables. Judgement should be made in relation to the research question at hand, specifically considering what other supplementary or competing theoretical explanations could exist. The third recommendation is to handle endogeneity using appropriate research design. Using institutional change as semi-natural experiment, combined with difference-in-difference approach, can be an effective way to reveal the true institutional effect, provided that the institutional change is itself exogenous to firms. Lastly, researchers should always assess and report the substantive significance of their findings in addition to statistical significance. Overstatement of institutional effects often happens when researchers are satisfied with finding a non-zero effect but fail to show how much it differs from zero. In relation to this last issue, I want to echo the recent calls from leading management journals (see Bettis et al., 2016; Lewin, 2016) to value rigorous replication studies including those producing none results as an important part of the cumulative work we conduct as academics to impact business practices and policies.

\section{GONGLUSION}

Can institutional influence on Chinese across-border M\&A be overstated? I argue that problems with the conceptualization of institutions, theorizing and testing institutional effects can lead research to produce unreliable findings that overstate the institutional effects. Buckley et al. (2016) starts with an important inquiry of the institutional influences from both the home and host countries on Chinese firms' cross-border M\&A activities. Through this commentary, I hope to raise the awareness of researchers regarding the potential theoretical and empirical pitfalls that may hinder the internal validity and external relevance of this line of scholarly inquiry. I do not take credit for identifying these pitfalls or the recommended solutions, as they are drawn from a wide range of scholarly works in the broad management field. My job is to link them with the issues illustrated in the paper and, in doing so, form a general guideline that may help future research advance this literature. I agree with Buckley et al. (2016) that we need to know more about institutional influence on Chinese outward FDI, for the theoretical potential and practical relevance of this line of research cannot be overstated, but we need to pursue this line of research without overstating our findings. 


\section{REFERENGES}

Ahmadjian, G. L. 2016. Comparative institutional analysis and institutional complexity.Journal of Management Studies, 53(1): 12-27.

Ang, S. H., Benischke, M. H., \& Doh, J. P. 2015. The interactions of institutions on foreign market entry mode. Strategic Management Journal, 36(10): 1536-1553.

Bettis, R. A., Ethiraj, S., Gambardella, A., Helfat, C., \& Mitchell, W. 2016. Creating repeatable cumulative knowledge in strategic management. Strategic Management Journal, 37(2): 257-261

Buckley, P., Yu, P., Liu, Q., Munjal, S., \& Tao, P. 2016. The institutional influence on the location strategies of multinational enterprises from emerging economies: Evidence from China's crossborder mergers and acquisitions. Management and Organization Revieze, 12(2): in press.

Cui, L., \& Jiang, F. M. 2012. State ownership effect on firms' FDI ownership decisions under institutional pressure: a study of Chinese outward-investing firms. Journal of International Business Studies, 43(3): 264-284.

Di Maggio, P.J., \& Powell, W. W. 1983. The iron cage revisited: Institutional isomorphism and collective rationality in organizational fields. American Sociological Revieze, 48(2): 147160.

Hall, P. A., \& Soskice, D. 2001. Varieties of capitalism: The institutional foundations of comparative advantage. Oxford: Oxford University Press.

Hotho, J. J., \& Pedersen, T. 2012. Institutions and international business research: Three institutional approaches and recommendations for future research. Progress in International Business Research, 7: 135-152.

Jackson, G., \& Deeg, R. 2008. Comparing capitalisms: Understanding institutional diversity and its implications for international business. Journal of International Business Studies, 39: 540-561.

Kostova, T., \& Hult, G. T. M. 2016. Meyer and Peng's 2005 article as a foundation for an expanded and refined international business research agenda: Context, organizations, and theories.Journal of International Business Studies, 47(1): 23-32.

Li, M. H., Cui, L., \& Lu, J. 2014. Varieties in state capitalism: Outward FDI strategies of central and local state-owned enterprises from emerging economy countries. Journal of International Business Studies, 45(8): 980-1004.

Meyer, J. W., \& Rowan, B. 1977. Institutionalized organizations: Formal structure as myth and ceremony. American Journal of Sociology, 83(2): 340-363.

Lin, Z., Peng, M. W., Yang, H. B., \& Sun, S. L. 2009. How do networks and learning drive M\&As? An institutional comparison between China and the United States. Strategic Management Journal, 30(10): 1113-1132.

Meyer, K. E., Estrin, S., Bhaumik, S. K., \& Peng, M. W. 2009. Institutions, resources, and entry strategies in emerging economies. Strategic Management Journal, 30(1): 61-80.

Meyer, K. E. \& Peng, M. W. 2016. Theoretical foundations of emerging economy research.Journal of International Business Studies, 47(1): 3-22.

Morck, R., Yeung, B., \& Zhao, M. 2008. Perspectives on China's outward foreign direct investment. Journal of International Business Studies, 39(3): 337-350.

Musacchio, A., Lazzarini, S. G., \& Aguilera, R. V. 2015. New varieties of state capitalism: Strategic and governance Implications. Academy of Management Perspectives, 29(1): 115-131.

Nelson, R. R., \& Sampat, B. N. 2001. Making sense of institutions as a factor shaping economic performance. Journal of Economic Behavior \& Organization, 44(1): 31-54.

North, D. G. 1990. Institutions, institutional change, and economic performance. Cambridge, MA: Harvard University Press.

Oliver, G. 1991. Strategic responses to institutional processes. Academy of Management Revieze, 16(1): 145-179.

Peng, M. W., Sun, S. L., Pinkham, B., \& Chen, H. 2009. The institution-based view as a third leg for a strategy tripod. Academy of Management Perspectives, 23(3): 63-81.

Peng, M. W., Wang, D. Y., \& Jiang, Y. 2008. An institution-based view of international business strategy: a focus on emerging economies. Journal of International Business Studies, 39(5): 920-936.

Schwab, A., Abrahamson, E., Starbuck, W. H., \& Fidler, F. 2011 . Researchers should make thoughtful assessments instead of null-hypothesis significance tests. Organization Science, 22(4): 11051120 . 
Scott, W. R. 1995. Institutions and organizations. London: Sage.

Spencer, J. W., Murtha, T. P., \& Lenway, S. A. 2005. How governments matter to new industry creation. Academy of Management Reviewe, 30(2): 321-337.

Whitley, R. 1999. Divergent capitalisms: The social structuring and change of business systems. Oxford: Oxford University Press.

Yang, H. B., Lin, Z., \& Lin, Y. 2010. A multilevel framework of firm boundaries: Firm characteristics, dyadic differences, and network attributes. Strategic Management Journal, 31(3): 237-261. 